\title{
Impact and Tensile Properties of Polyester Nanocomposites Reinforced with Conifer Fiber Cellulose Nanocrystal: A Previous Study Extension
}

\author{
Grazielle da Silva Maradini ${ }^{1}$, Michel Picanço Oliveira ${ }^{1}$ (D) Lilian Gasparelli Carreira ${ }^{2}$, Damaris Guimarães ${ }^{2}$, \\ Demetrius Profeti ${ }^{3}{ }^{\circledR}$, Ananias Francisco Dias Júnior ${ }^{1}{ }^{(}$, Walter Torezani Neto Boschetti ${ }^{4}$, \\ Bárbara Ferreira de Oliveira ${ }^{5}\left(\mathbb{D}\right.$, Artur Camposo Pereira ${ }^{6}(\mathbb{D})$ and Sergio Neves Monteiro ${ }^{6, *}$ \\ Citation: Maradini, G.d.S.; Oliveira, \\ M.P.; Carreira, L.G.; Guimarães, D.; \\ 1 Forest and Wood Sciences Department, Federal University of Espírito Santo, \\ Jeronimo Monteiro 29550-000, Brazil; graziellemaradini@gmail.com (G.d.S.M.); \\ michelpicanco@gmail.com (M.P.O.); ananiasjuniorr@gmail.com (A.F.D.J.) \\ 2 Rural Engineering Department, Federal University of Espírito Santo, Alto Universitário, sn., \\ Alegre 29500-000, Brazil; lcarreira83@gmail.com (L.G.C.); guimaraes.damaris@yahoo.com.br (D.G.) \\ 3 Chemistry and Physics Department, Federal University of Espírito Santo, Alto Universitário, sn., \\ Alegre 29500-000, Brazil; demetrius.profeti@ufes.br \\ 4 Department of Forest Engineering, Federal University of Viçosa, Viçosa 36570-900, Brazil; \\ walterboschetti@gmail.com \\ 5 Advanced Materials Department, Northern Fluminense State University Campos dos Goytacazes, \\ Campos dos Goytacazes 28013-602, Brazil; barbara.fo@gmail.com \\ 6 Military Institute of Engineering-IME, Materials Science Program, Praça General Tibúrcio 80, Urca, \\ Rio de Janeiro 22290-270, Brazil; camposo.artur@gmail.com \\ * Correspondence: snevesmonteiro@gmail.com or sergio.neves@me.eb.br
} Profeti, D.; Dias Júnior, A.F.; Boschetti, W.T.N.; Oliveira, B.F.d.; Pereira, A.C.; Monteiro, S.N. Impact and Tensile Properties of Polyester

Nanocomposites Reinforced with Conifer Fiber Cellulose Nanocrystal: A Previous Study Extension. Polymers 2021, 13, 1878. https://doi.org/ $10.3390 /$ polym 13111878

Academic Editor: Vincenzo Fiore

Received: 26 April 2021

Accepted: 31 May 2021

Published: 5 June 2021

Publisher's Note: MDPI stays neutral with regard to jurisdictional claims in published maps and institutional affiliations.

Copyright: (C) 2021 by the authors Licensee MDPI, Basel, Switzerland. This article is an open access article distributed under the terms and conditions of the Creative Commons Attribution (CC BY) license (https:/ / creativecommons.org/licenses/by/ $4.0 /)$.

\begin{abstract}
In a recent paper, novel polyester nanocomposites reinforced with up to $3 \mathrm{wt} \%$ of cellulose nanocrystals (CNCs) extracted from conifer fiber were characterized for their crystallinity index water absorption, and flexural and thermal resistance. The use of this novel class of nanocomposites as a possible substitute for conventional glass fiber composites (fiberglass) was then suggested, especially for the 1 and $2 \mathrm{wt} \% \mathrm{CNC}$ composites due to promising bending, density, and water absorption results. However, for effective engineering applications requiring impact and tensile performance, the corresponding properties need to be evaluated. Therefore, this extension of the previous work presents additional results on Izod and tensile tests of 1 and $2 \mathrm{wt} \% \mathrm{CNC}$-reinforced polyester composites, together with a comparative cost analysis with fiberglass. The chemical effect caused by incorporation of CNCs into polyester was also investigated by FTIR. In comparison to the neat polyester, the Izod impact energy increased $50 \%$ and $16 \%$ for the 1 and $2 \mathrm{wt} \%$ composites, respectively. On the other hand, the tensile strength and Young's modulus remained constant within the ANOVA statistical analysis. FTIR analysis failed to reveal any chemical modification caused by up to $2 \mathrm{wt} \% \mathrm{CNC}$ incorporation. The present impact and tensile results corroborate the promising substitution of a polyester composite reinforced with very low amount of CNCs for common fiberglass in engineering application.
\end{abstract}

Keywords: nanocomposite; chemical analysis; mechanical behavior; polyester; cellulose nanocrystal

\section{Introduction}

This century is experiencing an exponential increase in both the research works and industrial application of natural lignocellulosic fiber (NLF)-reinforced polymer matrix composites, as illustrated in the black squares curve in Figure 1 drawn by Luz et al. [1] from the Scopus database [2]. Particularly in recent decades, many researches have been carried out on composites reinforced with NFLs produced with fibers in different orientations, usually in amounts higher than $10 \%$ as well as their respective fabrics [3-6]. Another 
recently emerging potential use of NLF, indicated by the red circles curve in Figure 1, is through the extraction of its cellulose nanocrystals (CNCs) for the reinforcement of nanocomposites [7-15].

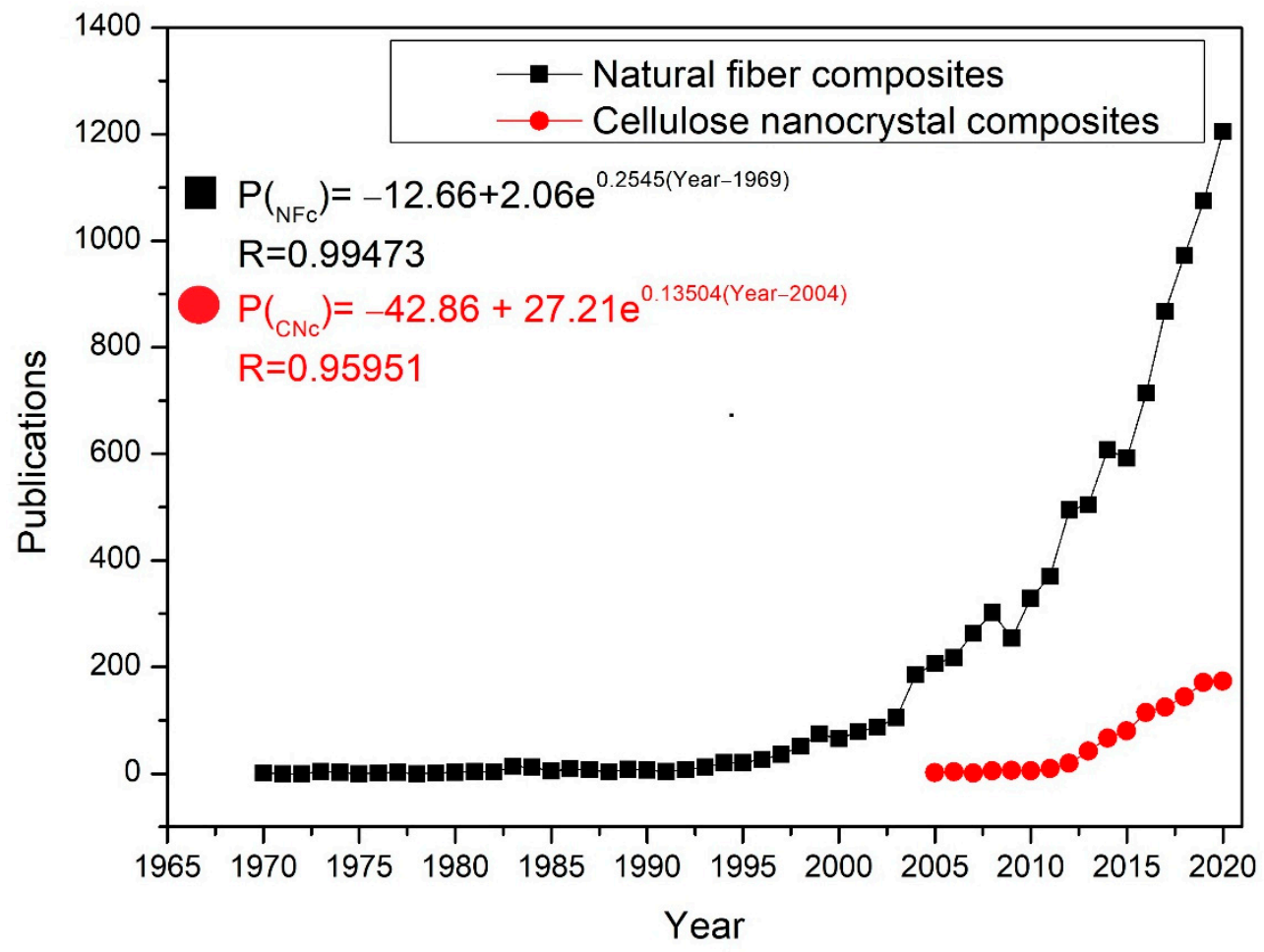

Figure 1. Correlations of the publications by the year of the natural fiber composites and cellulose nanocrystal composites.

In fact, CNCs display outstanding properties such as surface to volume ratios of $~ 100$, relatively low densities, and high mechanical strength $[14,15]$. According to Kargarzadeh et al. [14], CNCs can be easily modified as well as readily available, renewable, and biodegradable. They are rod-like particles with transverse dimensions as small as 3-30 $\mathrm{nm}$ [16] and lengths ranging between 100 and $1000 \mathrm{~nm}$. In contrast to NLF, the incorporation of CNCs into polymer matrices usually requires low percentages $(<10 \mathrm{wt} \%)$ to effectively reinforce nanocomposites [7-15] for a wide range of applications, including food packing and biomedical devices [8-16]. This has motivated the exponential rise of publications related to $\mathrm{CNC}$ nanocomposites in the past decade, as illustrated by the rede curve obtained from Scopus database in Figure 1.

Different NLFs, such as kenaf [14], sugar palm [17], soft and hard wood mixtures [18], rice husk [19], banana [20], sisal [21], and tunicin [22], have been used to isolate CNCs. Among the polymer matrices reinforced by these CNCs, unsaturated polyester is one of the thermoset resins that is most used for high-performance nanocomposites due to its room temperature (RT) cure associated with elevated strength, water resistance, and transparency properties [14]. However, the relatively low toughness of polyester limits its application as an engineering component subjected to impact. In contrast, polyester composites reinforced with more than $10 \mathrm{wt} \%$ of glass fiber, also called fiberglass, present an enhanced toughness that allows for applications in many industrial sectors, including aerospace and high-performance sports equipment, that require resistance to impact load [23-25].

A relevant point is the dispersion of hydrophilic CNCs into a hydrophobic polyester matrix. To prevent the aggregation of CNCs, surface modification by chemical coupling agents might not only improve dispersion but also enhance nanocomposite mechanical properties [26]. In the present work, a styrene monomer was used as coupling agent between a polyester matrix and CNCs following similar conditions used in a previous 
publication [27]. In that publication, polyester nanocomposites reinforced with 1, 2, and $3 \mathrm{wt} \%$ of CNCs extracted from conifer wood fiber were characterized for the crystallinity index and water absorption, as well as flexural and thermal resistance. The use of these novel nanocomposites was indicated as a possible substitute for conventional fiberglass in engineering applications. In particular, promising bending and thermal resistance preliminary results were found for the 1 and $2 \mathrm{wt} \% \mathrm{CNC}$ nanocomposites. However, for industrial applications requiring impact and standard tensile performance, other specific properties need to be evaluated together with a cost-effectiveness comparison with fiberglass. Thus, this work presents additional results on Izod and tensile tests, as well as a comparative cost analysis for the same [27] previously investigated 1 and $2 \mathrm{wt} \%$ CNC-reinforced polyester composites. Fourier transform infrared spectroscopy as used to investigate possible chemical effects caused by $\mathrm{CNC}$ incorporation into polyester.

\section{Materials and Methods}

\subsection{Materials}

The same materials previously investigated in [27] were used in this work. Briefly, unsaturated polyester resin (average molecular weight $\mathrm{Mn}=9 \times 10^{3} \mathrm{~g} / \mathrm{mol}$, a butanox catalyst (Mt 50), and a styrene monomer (coupling agent) were all supplied by Redelease, Brazil. Conifer fiber CNCs were provided by the Development Center of the University of Maine, Orono, ME, USA, with transverse dimensions of $3.0 \pm 0.5 \mathrm{~nm}$ and a length of $190 \pm 15 \mathrm{~nm}$.

\subsection{Processing of Nanocomposites}

Similar procedures described in [27] were caried out when processing the nanocomposites. Briefly, separate amounts of 1 and $2 \mathrm{wt} \%$ of CNCs were initially mixed with the styrene monomer and still fluid polyester $/ 1 \%$ butanox. The mixture was then poured into silicone molds with shapes and dimensions defined by the D256 [28] and D3039 [29] ASTM standards for Izod and tensile specimens, respectively. Four specimens were fabricated for each type of test and distinct amounts of CNCs, and they were finally cured at ambient temperature and pressure for $24 \mathrm{~h}$. The nanocomposites presented densification parameters associated with void volume fractions of $5.6,6.4$, and $7.0 \%$ for 0 (neat polyester), 1 , and $2 \mathrm{wt} \% \mathrm{CNC}$, respectively. Figure 2 schematically shows the composite fabrication process.

\subsection{Fourier Transform Infrared Analysis (FTIR)}

FTIR spectra were recorded at RT in a Bruker spectrometer, model Tensor 27 (Leipzig, Germany), by the attenuated total reflectance (ATR) technique. The powder samples were scanned in the range of $4000-600 \mathrm{~cm}^{-1}$ with a resolution of $4 \mathrm{~cm}^{-1}$. In this analysis, 32 scans were collected for each FTIR spectrum.

\subsection{Izod Impact Test}

Izod tests were carried out at RT for each CNC composition in a Pantech Instruments (São Paulo, Brazil), using a $11 \mathrm{~J}$ hammer pendulum. Prismatic standard [28] notched specimens with a depth of $2.54 \mathrm{~mm}$ and an angle of $45^{\circ}$ were fabricated using a Notchvas model CEAST carver. Four samples for each percentage of CNCs with dimensions of $62.5 \times 12.7 \times 10 \mathrm{~mm}$ were produced. Figure 3 shows schematics the specimens of the Izod tests.

\subsection{Tensile Test}

Tensile tests were conducted at RT on four standard [29] specimens for each CNC composition in a model DL 10.000 EMIC universal machine, (São José dos Pinhais, Brazil), operating with cross-head speed of $1 \mathrm{~mm} / \mathrm{min}$ until the specimen ruptured using a $1 \mathrm{kN}$ load cell. Typical specimens prepared for the tensile tests are shown in Figure 4. 


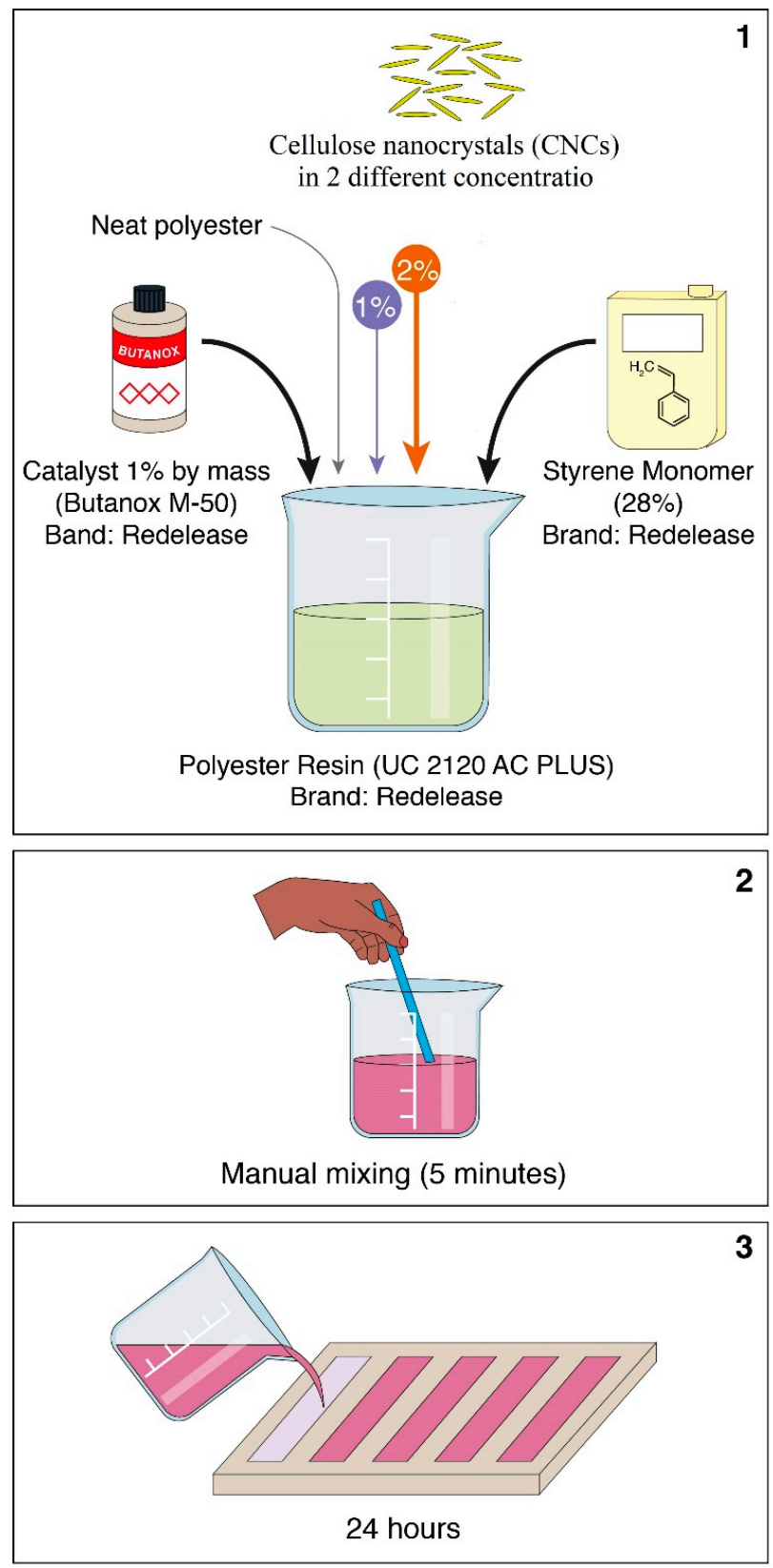

Figure 2. Schematic fabrication of unsaturated polyester composites reinforced with CNCs.

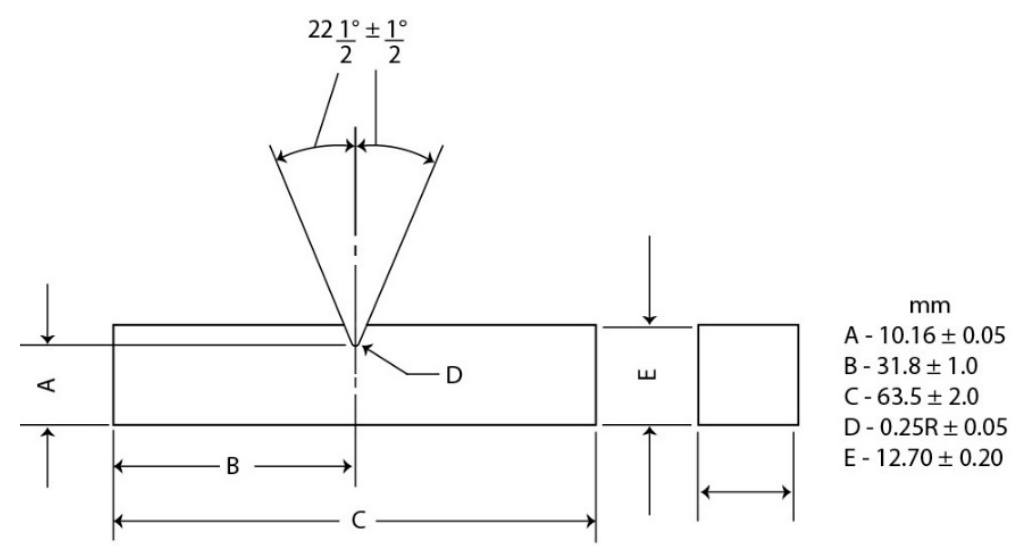

Figure 3. Schematic of dimensions of Izod-type test specimen according to the standard. 


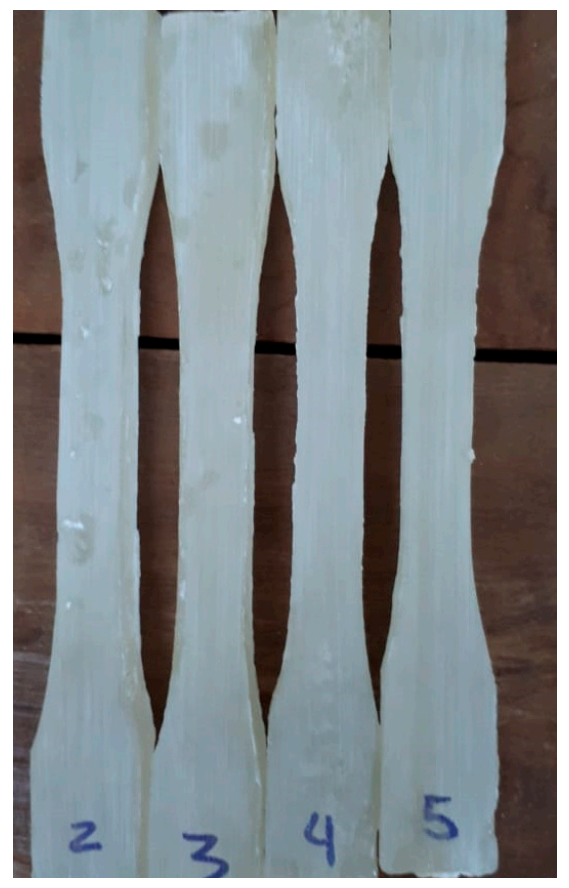

Figure 4. Specimens nanocomposites with $1 \mathrm{wt} \%$ of CNCs for tensile test.

\subsection{Statistical Analysis}

The analysis of variance (ANOVA) was applied to test the hypothesis of equality, and a lower significant difference Tukey test was applied for the Izod and Young's modulus and ultimate tensile strength, both with $95 \%$ confidence level, results.

\section{Results and Discussion}

\subsection{Fourier Transform Infrared Analysis Spectroscopy (FTIR)}

Figure 5 shows the FTIR spectra of plain CNC (Figure 5a) and polyester nanocomposites reinforced with 1 and $2 \mathrm{wt} \%$ of CNCs and neat polyester (Figure $5 b$ ).
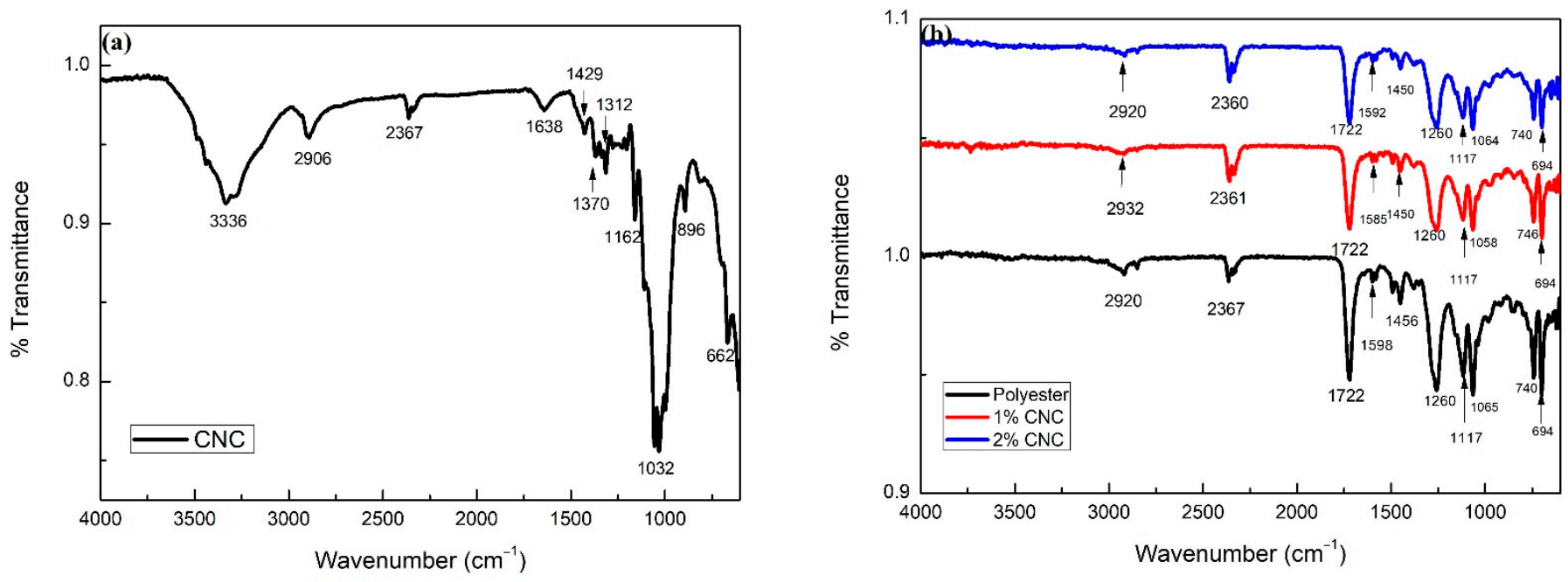

Figure 5. FTIR spectra of (a) plain CNC and (b) polyester nanocomposites, as well as neat polyester.

In Figure $5 \mathrm{a}$, the wide band at $3336 \mathrm{~cm}^{-1}$ is related to the $\mathrm{O}-\mathrm{H}$ group vibration with strong intramolecular $\mathrm{H}$ bonds, which may have been associated with the alcohols, extracts, and carboxylic acids that make up cellulose. In some cases, due to the crystalline or hindrance steric structure, the hydroxyl group was not hydrogen-bonded. For this reason, 
a resultant weak band appeared between 3500 and $3300 \mathrm{~cm}^{-1}$, as observed in the cellulose FTIR spectrum of Figure 5a. Moreover, the weak intensity of the $\mathrm{OH}$ band is usually found when an ATR accessory is used for the IR measurements of polymers. A typical cellulose FTIR/ATR spectrum was shown in the study of Larkin [30], which corroborated the CNC profile obtained in our work. It is important to mention that these CNC nanocomposites showed an irrelevant water absorption of only $0.2 \%$, as reported in our previous work [27]. The $2906 \mathrm{~cm}^{-1}$ band corresponds to the $\mathrm{C}-\mathrm{H}$ bonds, which are characteristic of organic molecules found in natural components. The weak band around $2367 \mathrm{~cm}^{-1}$ refers to the $\mathrm{CO}_{2}$ present in the atmosphere during the analysis. The band at $1638 \mathrm{~cm}^{-1}$ is related to $\mathrm{OH}$ groups and water molecules absorbed onto the $\mathrm{CNC}$ surface [31-33]. The bands at 1429 and $1312 \mathrm{~cm}^{-1}$ can be attributed to symmetric angular strain in the plane of the $\mathrm{CH}_{2}$ group and symmetrical angular strain in the plane of the $\mathrm{CH}_{2}$ groups, respectively. The band around $1370 \mathrm{~cm}^{-1}$ can be attributed to the $\mathrm{C}-\mathrm{H}$ strain. The band at $1162 \mathrm{~cm}^{-1}$ corresponds to the angular deformation of the $\mathrm{C}-\mathrm{O}$ connections of the esters existing in the $\mathrm{CNC}$. The bands at 1032 and $896 \mathrm{~cm}^{-1}$ indicate the purity of the crystalline cellulose. The band at $1032 \mathrm{~cm}^{-1}$ is attributed to the vibrations of the C-O. The band at $896 \mathrm{~cm}^{-1}$ is related to the axial deformation of the $\mathrm{C}-\mathrm{O}-\mathrm{C}$ bonds and $\beta$-glycosidic bonds present between the cellulose glucose groups [34-36]. The band around $662 \mathrm{~cm}^{-1}$ may be assigned to the -CHbonding of aromatic groups [32].

It is worth noting that the CNC spectrum in Figure 5a displays transmittance at 1429, 1162 , and $896 \mathrm{~cm}^{-1}$, indicating that the nanocellulose produced before acid hydrolysis was in the form of cellulose I, which corresponds to native cellulose [34-37]. In Figure 5b, it can be observed that the unsaturated polyester had a weak band at $2920 \mathrm{~cm}^{-1}$, which can be attributed to the $\mathrm{C}-\mathrm{H}$ elongation. The weak band around $2367 \mathrm{~cm}^{-1}$ refers to the $\mathrm{CO}_{2}$ present in the atmosphere during the analysis, and the band at $1456 \mathrm{~cm}^{-1}$ is not associated with any functional group present in the unsaturated polyester. The polyester showed important characteristic absorption in the $1722 \mathrm{~cm}^{-1}$ band, which represents the carbonyl group, $\mathrm{C}=\mathrm{O}$. The bands close to 1598 and $740 \mathrm{~cm}^{-1}$ represent the elongation of the aromatic nucleus $\mathrm{C}=\mathrm{C}$. This occurred due to the presence of the unsaturated double bond $(\mathrm{C}=\mathrm{C})$ in the polyester and refers to the vinyl group present in the styrene monomer. The bands close to 1260 and $1117 \mathrm{~cm}^{-1}$ occurred due to stretching vibrations $\mathrm{C}-\mathrm{O}-\mathrm{C}$ connected to the aliphatic and aromatic groups, respectively [38,39]. The bands at 1065 and $694 \mathrm{~cm}^{-1}$ can be assigned, respectively, to the aromatic $\mathrm{C}-\mathrm{H}$ ring in the plane and the aromatic $\mathrm{C}=\mathrm{C}$ ring in the plane [38].

The FTIR spectra in Figure 5 of polyester nanocomposites reinforced with 1 and $2 \mathrm{wt} \%$ of CNCs show absorption bands similar to those of the polyester without reinforcement. This indicates that the incorporation CNCs into the polyester did not significantly change the chemical structure However, there were minor variations in the frequencies of the absorption bands of the nanocomposites in comparison to those of the polyester. These observed changes in the bands may indicate reinforcement load interactions with the matrix $[39,40]$.

\subsection{Izod Impact Strength}

Figure 6 shows the variation of Izod absorbed impact energy with CNC content in unsaturated polyester matrix. A significant increase of $50 \%$ was obtained with the addition of $1 \mathrm{wt} \%$ of CNCs into the polyester matrix, which proved a reinforcement effect in impact strength. For the $2 \mathrm{wt} \% \mathrm{CNC}$ nanocomposites, the average absorber impact energy showed an increase of $16 \%$. However, the relatively higher standard deviations (error bars) did not guarantee a reinforcement effect. An important comparison might be done with the CNC (isolated from kenaf bast fiber)-reinforced unsaturated polyester nanocomposite impact energy results of Kargarzadeh et al. [14]. Though their impact test was performed with unnotched specimens, which gave comparatively higher impact strengths for the polyester matrix, the incorporation of $2 \mathrm{wt} \%$ of CNCs increased the impact energy by $14 \%$. Another relevant point discussed by the authors was the fact that the incorporation of inorganic 
nanoparticles such as $5 \mathrm{wt} \% \mathrm{Al}_{2} \mathrm{O}_{3}$ [41] and $2 \mathrm{wt} \%$ nonclay [42] into unsaturated polyester improved the impact resistance by $11 \%$ and $20 \%$, respectively. Thus, the results presented in Figure 3 corroborate the conclusion of Kargarzadeh et al. [14] that CNC has the potential to be used as an impact modifier for different types of polyester nanocomposites

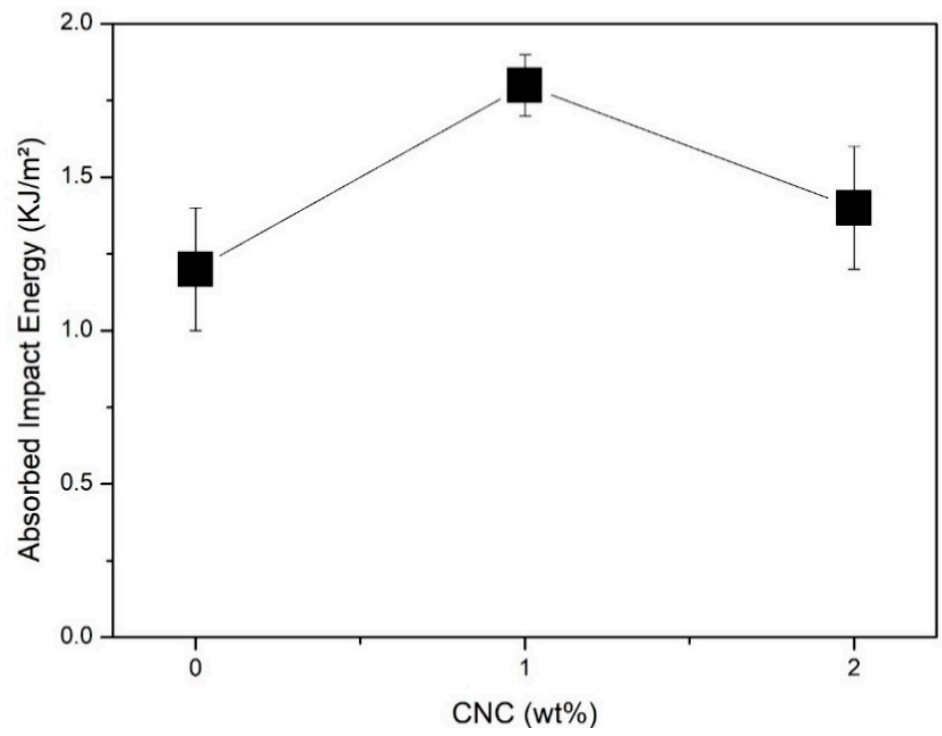

Figure 6. Variation of the Izod absorbed impact energy of unsaturated polyester nanocomposite notched specimens with CNC content.

Regarding these findings in CNC-reinforced polyester nanocomposites, it is worth mentioning that Bindal et al. [23] reported a much lower impact strength of polyester reinforced with $20 \mathrm{wt} \%$ of glass fiber. A question that may arise from the results in Figure 6 is the reason for the decrease in impact strength in going from 1 to $2 \mathrm{wt} \%$ of CNCs. According to Peng et al. [43], nanocomposite impact strength decreases with increasing additions of $\mathrm{CNC}$, which may be due to the agglomeration of nanoparticles. Therefore, as evidence in Figure 6, there is no need to reinforce a polyester matrix with more than $2 \mathrm{wt} \%$ of conifer fiber $\mathrm{CNC}$ to obtain a significant impact strength to compete with nanocomposites reinforced with inorganic nanoparticles or fiberglass at cost-effective conditions.

Another question regarding the values and corresponding error bars in Figure 6 is the effective reinforcement caused by the incorporation of $\mathrm{CNC}$ into polyester matrix. The ANOVA comparing neat polyester $(0 \mathrm{wt} \%)$ and the $1 \mathrm{wt} \% \mathrm{CNC}$ nanocomposite showed that $\mathrm{F}_{\text {cal. }}$ (19.5923) $>\mathrm{F}_{\text {crit }}$ (5.98737), which indicated that their impact strengths were different with $95 \%$ of confidence.

From the Tukey test results, it was possible to affirm with a $95 \%$ level of confidence that the impact strength of the $1 \mathrm{wt} \% \mathrm{CNC}$ nanocomposite was higher not only than that of the neat polyester but also the $2 \mathrm{wt} \% \mathrm{CNC}$ nanocomposite. Moreover, both neat polyester and the $2 \mathrm{wt} \% \mathrm{CNC}$ composite had similar impact strengths.

\subsection{Tensile Test}

Figure 7 show the variation of (Figure 7a) tensile strength and (Figure 7b) Young's modulus with conifer fiber $\mathrm{CNC}$ content in unsaturated polyester nanocomposites. In Figure $7 \mathrm{a}$, one can notice a maximum in the average value of the tensile strength with the incorporation of $1 \mathrm{wt} \%$ of CNCs. However, due to the relatively higher standard deviation associated with the neat polyester, it is not possible to assert the existence of this maximum.

The ANOVA for the CNCs contents of 0 (neat polyester), 1, and $2 \mathrm{wt} \%$ revealed an $\mathrm{F}_{\text {cal }}(2.742)<\mathrm{F}_{\text {crit }}(4.256)$, indicating no difference between the corresponding tensile strengths with a $95 \%$ level of confidence. In this case, there was no need to perform the Tukey test. 

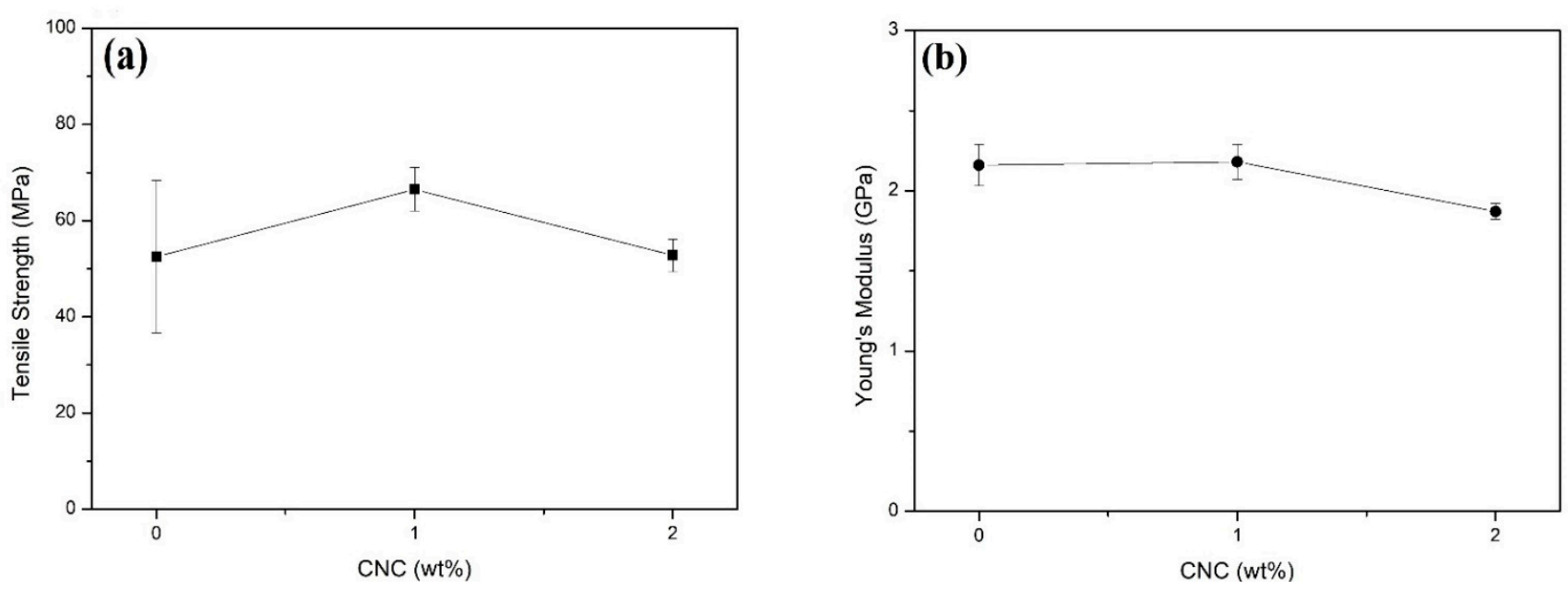

Figure 7. Variation of (a) tensile strength and (b) Young's modulus of unsaturated nanocomposites with conifer fiber CNC content.

As for the Young's moduli in Figure 7b, there was no apparent increase with $1 \mathrm{wt} \%$ conifer fiber CNC compared to the neat polyester. However, an average decrease of $\sim 15 \%$ occurred for the $2 \mathrm{wt} \% \mathrm{CNC}$ composite as compared to the neat polyester. The ANOVA for the three CNCs contents of 0,1 , and $2 \mathrm{wt} \%$ revealed an $\mathrm{F}_{\text {cal }}(11.813)>\mathrm{F}_{\text {crit }}(4.256)$, indicating, with a $95 \%$ level of confidence, that there was a significant difference between the Young's moduli in Figure $7 \mathrm{~b}$.

In order to verify the origin of the difference detected by the ANOVA, a corresponding Tukey test was performed. From the results, it is possible to affirm with a $95 \%$ level of confidence that the Young's moduli of 0 (neat polyester) and $1 \mathrm{wt} \% \mathrm{CNC}$ composites were similar but different to that of the $2 \mathrm{wt} \%$ CNC composite.

It is worth mentioning that Kargarzadeh et al. [14] found no increase in both tensile strength and Young's modulus with the incorporation of $2 \mathrm{wt} \%$ kenaf fiber CNC compared to an unsaturated polyester matrix. The authors did not investigate $1 \mathrm{wt} \%$ CNC nanocomposites.

Based on the results shown in Figures 6 and 7, one could conclude that $1 \mathrm{wt} \%$ conifer fiber $\mathrm{CNC}$ is able to reinforce a polyester matrix. This finding was corroborated by the results of Cherayil et al. [42], which also suggested that $0.5 \mathrm{wt} \%$ conifer fiber CNC might even be a better reinforcement. On the other hand, common polyester composites reinforced with more than $10 \mathrm{wt} \%$ of glass fiber (fiberglass) usually display higher tensile strengths than those of the aforementioned results reported in [14,42] and Figure 7 However, Bindal at al. [23] disclosed a tensile strength of $62.2 \mathrm{MPa}$ for a polyester composite with $20 \mathrm{wt} \%$ of glass fiber, which was slightly lower than the present value of $65.6 \mathrm{MPa}$ for a $1 \mathrm{wt} \%$ conifer fiber CNC polyester nanocomposite.

Despite the difference in mechanical properties, one important factor in deciding to substitute a CNC nanocomposite for fiberglass is the comparative cost of materials. For this purpose, Table 1 presents a preliminary cost analysis of the present polyester nanocomposite with $1 \mathrm{wt} \%$ of conifer fiber $\mathrm{CNCs}$ and the glass fiber-reinforced polyester composites of Bindal et al. [23].

The results of the cost analysis in Table 1 show that the nanocomposite with $1 \mathrm{wt} \%$ of CNCs, despite the very low amount of filler, would always be more expensive due to the greater price of polyester. However, the difference in price is negligible and might never be a factor in engineering application decisions. On the other hand, technical factors such as impact strength (Figure 6), which favor CNC nanocomposites over glass fiber composites [23], might be decisive factors in specifying applications like aerospace components and high-performance sport equipment. 
Table 1. Comparative cost analysis between the present polyester nanocomposite with $1 \mathrm{wt} \%$ of conifer fiber $\mathrm{CNC}$ and the polyester composites reinforced with glass fiber.

\begin{tabular}{ccc}
\hline Precursor Materials & Price (US\$/Kg) & Ref \\
\hline Unsaturated Polyester & 11.10 & {$[44]$} \\
E Glass Fiber & 6.90 & {$[45]$} \\
Conifer Fiber CNC & 8.16 & [present work] \\
\hline Investigated Materials & Calculation & Final Cost (US\$/Kg) \\
\hline $1 \mathrm{wt} \%$ Conifer fiber CNC/Polyester & $0.01 \times 8.16+0.99 \times 11.10$ & 11.07 \\
$20 \mathrm{wt} \%$ Glass Fiber/Polyester & $0.2 \times 6.90+0.80 \times 11.10$ & 10.26 \\
$30 \mathrm{wt} \%$ Glass Fiber/Polyester & $0.3 \times 6.90+0.70 \times 11.10$ & 9.84 \\
$40 \mathrm{wt} \%$ Glass Fiber/Polyester & $0.4 \times 6.90+0.60 \times 11.10$ & 9.42 \\
\hline
\end{tabular}

Moreover, it is important to emphasize that glass fiber composites are highly anisotropic, which could limit their applications in certain engineering conditions. In contrast, $\mathrm{CNC}$ composites are isotropic, which opens more engineering possibilities.

\section{Summary and Conclusions}

Additional results for unsaturated polyester nanocomposites reinforced with 1 and $2 \mathrm{wt} \%$ of CNCs are presented here as an extension of previous work [27]. FTIR spectra revealed that the small incorporation of $\mathrm{CNC}$ did not significantly alter the chemical structure of the polyester matrix. The observed changes in bands might indicate filler interaction with the matrix.

- An increase of $50 \%$ in the impact strength was obtained for the $1 \mathrm{wt} \% \mathrm{CNC}$ nanocomposite, which proved to be an effective reinforcement with respect to neat polyester. For the $2 \mathrm{wt} \% \mathrm{CNC}$ composite, the $16 \%$ increase in the average value had standard deviations coinciding with that of polyester and were not found be different via the ANOVA and Tukey test.

- The tensile strength and Young's modulus of the $1 \mathrm{wt} \% \mathrm{CNC}$ nanocomposite were not different than those of neat polyester, as supported by the ANOVA and Tukey test. On the other hand, the Young's Modulus of the $2 \mathrm{wt} \%$ nanocomposite decreased by $15 \%$ if compared to the neat polyester.

- A preliminary cost analysis found that since polyester is the most expensive precursor, the $1 \mathrm{wt} \% \mathrm{CNC}$ nanocomposite and glass fiber composites are equally cost-effective.

- Other factors such as impact strength and CNC renewability would favor the present nanocomposite for specific applications in high-performance sport equipment.

Author Contributions: G.d.S.M. prepared the testing specimens, analyzed the data, and wrote the paper; W.T.N.B. prepared testing specimens and performed the tests; L.G.C., A.F.D.J., D.G., D.P., A.C.P., and B.F.d.O. performed the formal analysis validation and visualization; S.N.M. wrote and reviewed the paper; M.P.O. conceived and coordinated the project and reviewed the paper. All authors have read and agreed to the published version of the manuscript.

Funding: This research was funded by the Brazilian agencies: CNPq (grant numbers: 432023/2018-6) and the Fundação de Amparo à Pesquisa e Inovação do Espírito Santo State Foundation for Support Research and Innovation (FAPES), Brazil (grant numbers: FAPES 184/2019- EDITAL FAPES No 21/2018-UNIVERSAL). This study was financed in part by the Coordenação de Aperfeiçoamento de Pessoal de Nível Superior-Brasil (CAPES)-Finance Code 001.

Data Availability Statement: The data presented in this study are available on request from the corresponding author.

Acknowledgments: The authors thank the support to this investigation by the Brazilian agencies: CNPq, CAPES and FAPES.

Conflicts of Interest: The authors declare no conflict of interest. 


\section{References}

1. Luz, F.S.; Garcia Filho, F.C.; Del-Rio, M.T.C.; Nascimento, L.F.C.; Pinehro, W.A.; Monteiro, S.N. Graphene-Incorporated Natural Fiber Polymer Composites: A First Overview. Polymers 2020, 12, 1601. [CrossRef]

2. Scopus Database. Available online: www.scopus.com/search/form.uri\#basic (accessed on 22 April 2021).

3. Aisyah, H.A.; Peridah, M.T.; Sapuan, S.M.; Ilyas, R.A.; Khalina, A.; Nurazzi, N.M.; Lee, S.H.; Lee, C.H. A comprehnsive review on advanced sustainable woven natural fiber polymer composites. Polymers 2021, 13, 471. [CrossRef] [PubMed]

4. Zhang, Z.; Cai, S.; Li, Y.; Wang, Z.; Long, Y.; Yu, T.; Shen, Y. High performances of plant fiber reiforced composites a new insight from hierarchical microstructures. Compos. Sci. Techinol. 2020, 194, 10815.

5. Rajak, D.K.; Pagar, D.D.; Menezes, P.L.; Linul, E. Fiber-reinforced polymer composites: Manufacturing, properties, and applications. Polymers 2019, 11, 1667. [CrossRef] [PubMed]

6. Sanjay, M.R.; Madhu, P.; Jawaid, M.; Senthamaraikannan, P.; Senthil, S.; Pradeep, S. Characterization and properties of natural fiber polymer composites: A comprehensive review. J. Clean. Prod. 2018, 172, 566-581. [CrossRef]

7. Nagarajan, K.J.; Ramanujam, N.R.; Sanjay, M.R.; Siengchin, S.; Surya Rajan, B.; Sathick Basha, K.; Madhu, P.; Raghav, G.R. A comprehensive review on cellulose nanocrystals and cellulose nanofibers: Pretreatment, preparation, and characterization. Polym. Compos. 2021, 42, 1588-1630. [CrossRef]

8. Vanderfleet, O.M.; Cranston, E.D. Production routes to tailor the performance of cellulose nanocrystals. Nat. Rev. Mater. 2021, 6, 124-144. [CrossRef]

9. Zheng, T.; Pilla, S. Melt procesing of cellulose nanocrystal-foller composites; Toward reiforcement and foum nucleation. Ind. Eng. Clem. Res. 2020, 59, 8511-8531. [CrossRef]

10. Huang, S.; Liu, X.; Chang, C.; Wang, Y. Recent developments and prospective food-related applications of cellulose nanocrystals: A review. Cellulose 2020, 27, 2991-3111. [CrossRef]

11. Gong, X.; Kalantari, M.; Aslanzadeh, S.; Boluk, Y. Interfacial interaction and eletrospinning of cellulose nanocrystal dispersions in polyer solution: A review. J. Dispers. Sci. Technol. 2020, 1-33. [CrossRef]

12. Isogai, A. Cellulose nanofiber: Recent progress and future prospects. J. Fiber Sci. Thechnol. 2020, 70, 310-326. [CrossRef]

13. Ilyas, R.A.; Sapuan, S.N.; Iskak, M.R.; Zaimudin, E.S. Nanocrystalline cellulose as reiforment for polymeric matrix nanocomposites and its potential applications: A review. Curr. Anal. Chem. 2018, 14, 203-225. [CrossRef]

14. Kargarzadeh, H.; Sheltami, R.M.; Ahmad, I.; Abdullah, I.; Dufresne, A. Cellulose nanocrustal: A promising toughening agent for unsaturated polyester nanocomposite. Polymer 2015, 56, 346-357. [CrossRef]

15. Ng, H.M.; Sin, L.T.; Tee, T.T.; Bee, S.T.; Hui, D.; Low, C.Y.; Rahmat, A.R. Extraction of cellulose nanocrystals from plant sources for application as reinforcing agent in polymers. Compos. Part B Eng. 2015, 75, 176-200. [CrossRef]

16. Eichhorn, S. Cellulose nanowhiskers: Promising materials for advanced applications. Soft Matter 2011, 7, 303-315. [CrossRef]

17. Ilyas, R.A.; Sapuan, S.M.; Ishak, M.R.; Zainudin, E.S. Development and characterization of sugar palm nanocrystalline cellulose reinforced sugar palm starch bionanocomposites. Carbohydr. Polym. 2018, 202, 186-202. [CrossRef]

18. Korotkov, A.N.; Voskoboinikov, I.V.; Konstantinova, S.A.; Gal'braikh, L.S.; Mikhailov, A.I. Some observations on obtaining cellulose nanocrystals. Fibre Chem. 2012, 43, 339-343. [CrossRef]

19. Johar, N.; Ahmad, I.; Dufresne, A. Extraction preparation and characterization of cellulose fibers and nanocrystals from rice hunks. Ind. Chop. Prod. 2012, 37, 93-99. [CrossRef]

20. Deepa, B.; Abraham, E.; Cherian, B.M.; Bismark, A.; Blaker, J.J.; Pothan, I.A.; Leao, A.L.; Souza, S.F.; Kottaisamy, M. Structure, morphology and thermal characterization of banana fiber obtained by steam explosion. Bioresou. Technol. 2010, 102, 1988-1997. [CrossRef]

21. Morán, J.I.; Alvarez, V.A.; Cyras, V.P.; Vazquez, A. Extraction of cellulose and preparation of nanocellulose from sisal fibers. Cellulose 2008, 159, 149-159. [CrossRef]

22. Azazi Samir, M.A.S.; Alloin, F.; Sanchez, J.-Y.; Dufresne, A. Cellulose nanocrystal reiforced polycoxythelene. Polymer 2004, 45, 4149-4157. [CrossRef]

23. Bindal, A.; Singh, S.; Batra, N.K.; Khanna, R. Development of glass/jute fiber reinforced polyester composite. Indian J. Mater. Sci. 2013, 6, 1-6. [CrossRef]

24. Leonard, L.W.H.; Wong, K.J.; Low, K.O.; Yousif, B.F. Fracture behavior of glass fiber-reinforced polyester composite. Proceeding of the institution of Mechanical Engineers Part L. J. Mater. Des. Appl. 2009, 223, 83-89. [CrossRef]

25. Borgaonkara, A.V.; Mandaleb, M.B.; Potdarc, S.B. Effect of Changes in Fiber Orientations on Modal Density of Fiberglass Composite Plates. Mater. Today Proc. 2018, 5, 5783-5791. [CrossRef]

26. Roman, M.; Winter, W.T. Cellulose nanocrystal for thermoplastic reinforcement: Effect of filler surface chemistry on composite properties. In Cellulose Nanocomposites; Oksman, K., Sain, M., Eds.; American Chemical Socity: Washington, DC, USA, 2006; Volume 938, pp. 99-113.

27. Maradini, G.d.S.; Oliveira, M.P.; Guanaes, G.M.d.S.; Passamani, G.Z.; Carreira, L.G.; Boschetti, W.T.N.; Monteiro, S.N.; Pereira, A.C.; de Oliveira, B.F. Characterization of Polyester Nanocomposites Reinforced with Conifer Fiber Cellulose Nanocrystals. Polymers 2020, 12, 2838. [CrossRef]

28. American Society for Testing and Materials. ASTM D256-10; Standart Test Methodo for Determining the Izod Pendulum Impact Resistence of Plastic; ASTM: West Conshohocken, PA, USA, 1995. 
29. American Society for Testing and Materials. ASTM D3039-95; Standart Test Methodo for Tensile Properties of Polymers Matrix Composite Materials; ASTM: West Conshohocken, PA, USA, 1995.

30. Larkin, P. Infrared and Raman Spectroscopy: Principles and Spectral Interpretation; Elsevier: San Diego, CA, USA, 2011.

31. Movva, M.; Kommineni, R. Extraction of cellulose from pistachio shell and physical and mechanical characterisation of cellulosebased nanocomposites. Mater. Res. Express 2017, 4, aa6863. [CrossRef]

32. Souza, D.R.S.; Mesquita, J.P.; Lago, R.M.; Caminhas, L.D.; Pereira, F.V. Cellulose nanocrystals: A versatile precursor for the preparation of different carbon structures and luminescent carbon dots. Ind. Crops Prod. 2016, 93, 121-128. [CrossRef]

33. Monteiro, S.N.; Margem, F.M.; Simonassi, N.T.; Loiola, R.L.; Oliveira, M.P. Characterization of curaua fibers by infrared spectroscopy. Mater. Sci. Forum 2014, 775-776, 325-329. [CrossRef]

34. Li, M.; Zhao, X.; Li, Y.; Wang, W.; Zhong, W.; Luo, M.; Lu, Y.; Liu, K.; Liu, Q.; Wang, Y.; et al. Synergistic improvement for mechanical, thermal and optical properties of PVA-co-PE nanofiber/epoxy composites with cellulose nanocrystals. Compos. Sci. Technol. 2020, 188, 107990. [CrossRef]

35. Parize, D.D.S.; Oliveira, J.E.; Williams, T.; Wood, D.; Avena-Bustillos, R.J.; Klamczynski, A.P.; Glenn, G.M.; Marconcini, J.M.; Mattoso, L.H.C. Solution blow spun nanocomposites of poly(lactic acid)/cellulose nanocrystals from Eucalyptus kraft pulp. Carbohydr. Polym. 2017, 174, 923-932. [CrossRef]

36. Souza, A.G.; Kano, F.S.; Bonvent, J.J.; Rosa, D.S. Cellulose nanostructures obtained from waste paper industry: A comparison of acid and mechanical isolation methods. Mater. Res. 2017, 20, 209-214. [CrossRef]

37. Chen, Y.W.; Lee, H.V.; Juan, J.C.; Phang, S.M. Production of new cellulose nanomaterial from red algae marine biomass Gelidium elegans. Carbohydr. Polym. 2016, 151, 1210-1219. [CrossRef]

38. Abdullah, N.M.; Ahmad, I. Potential of using polyester reinforced coconut fiber composites derived from recycling polyethylene terephthalate (PET) waste. Fibers Polym. 2013, 14, 584-590. [CrossRef]

39. Bora, C.; Bharali, P.; Baglari, S.; Dolui, S.K.; Konwar, B.K. Strong and conductive reduced graphene oxide/polyester resin composite films with improved mechanical strength, thermal stability and its antibacterial activity. Compos. Sci. Technol. 2013, 87, 1-7. [CrossRef]

40. García del Pino, G.; Kieling, A.C.; Bezazi, A.; Boumediri, H.; Rolim de Souza, J.F.; Valenzuela Díaz, F.; Valin Rivera, J.L.; Dehaini, J.; Panzera, T.H. Hybrid Polyester Composites Reinforced with Curauá Fibres and Nanoclays. Fibers Polym. 2020, 21, 399-406. [CrossRef]

41. Baskaran, R.; Saruhadevi, M.; Vijayakumar, C.T. Unsaturated polyester nanocomposite filled with alunuba. J. Mater. Sci. 2011, 46, 4846-4871. [CrossRef]

42. You, C.J.; Xu, J.G.; Zeng, Y.Z.; Li, Y.; Jia, D.M.; Nishi, T. Morphology and performance of unsaturated polyester nanocomposites modified with organoclay and thermoplastic polyuretane. Chin. J. Polym. Sci. 2010, 28, 913-922. [CrossRef]

43. Peng, Y.; Gardner, D.J.; Han, Y. Characterization of mechanical and morphological properties of cellulose reinforced polyamide 6 composites. Cellulose 2015, 22, 3199-3215. [CrossRef]

44. Fiberglass Site. Available online: http:/ / fiberglasssite.com/polyester-resin/ (accessed on 22 April 2021).

45. Fiberglass Site. Available online: http:/ / fiberglasssite.com/chopped-strands/ (accessed on 22 April 2021). 